\title{
Finding the 'missing millions': do we need incentives to optimise COPD outcomes?
}

\section{See linked article by Falzon et al. on pg 59}

\section{*June Roberts', Stephen Gaduzo²}

1 Respiratory Nurse Consultant, Salford Royal NHS Foundation Trust, Salford, Manchester, UK; North-West of England Strategic Health Authority Respiratory Clinical Lead

2 General Practitioner, Cheadle Medical Practice, Manchester, UK; North-West of England Strategic Health Authority Respiratory Clinical Lead; Chairman-elect, PCRS-UK Executive

*Correspondence: Mrs June Roberts, Respiratory Nurse Consultant, Department of Respiratory Medicine, Salford Royal NHS Foundation Trust, Room 336 Clinical Sciences Building, Stott Lane, Salford, Greater Manchester, M6 8HD, UK Tel: +44 (0)1612063156 Fax: +44 (0)1612064189 E-mail: june.roberts@nhs.net

Under-diagnosis of COPD remains an international problem. ${ }^{1,2}$ Less than one-third of the predicted three million people in the UK with COPD currently have a diagnosis. ${ }^{1}$ Furthermore, there is wide and unwarranted variation in the proportion of those who have a diagnosis versus those who remain undiagnosed, with deprived populations having both the highest prevalence and the highest under-diagnosis of COPD. ${ }^{12}$ This is important, since the diagnosis of COPD is often made late when significant lung function has been lost, when exacerbations and hospitalisations are more common, quality of life is notably affected, and the costs of managing the disease are significant. ${ }^{3}$

Given that awareness of COPD is low, both amongst primary care clinicians and patients, ${ }^{4}$ it is not surprising that the early identification of people with clinically relevant COPD is central to disease management guidelines and health policy. ${ }^{5.8}$ In this issue of the $P C R J$, Falzon et al. describe the use of a locally enhanced service (LES) in one particular Primary Care Trust (PCT) in the UK that uses financial incentives to drive up COPD diagnosis rates. ${ }^{9}$

Evidence to support the use of financial incentives to improve performance in healthcare is so far modest and inconsistent. ${ }^{10}$ Critics have even suggested that such incentives are controlling and may undermine and even worsen performance, especially when intrinsic motivation is high to begin with. "1 Yet, finding ways to motivate and engage over-burdened primary care clinicians in the management of chronic diseases remains challenging. In the UK National Health Service (NHS), the new Clinical Commissioning Groups (CCGs), led by primary care clinicians, will have the remit to drive improvement by setting priorities and influencing the provision of care in order to obtain positive health outcomes in their localities. Improvements in COPD care should be high on their agenda; CCGs are specifically tasked with reducing mortality in respiratory disease as well as reducing the time people with long-term conditions spend in hospital, both of which are more likely to be achieved if people are diagnosed early and treated appropriately. ${ }^{8}$

Critics of early diagnosis initiatives rightly highlight that smoking is the major cause of COPD and that almost all cases could be prevented, or disease progression lessened, by patients quitting. ${ }^{12}$ Furthermore, the ability of primary care to perform and interpret spirometry accurately has been questioned. However, although all smokers should be advised to quit, utilising lung function measures can enhance quit rates in those with COPD, and it is entirely possible to assure the quality of spirometry in primary care settings. ${ }^{13,14}$

Therefore, financial incentives for COPD case-finding should at least be tied to the provision of smoking cessation support and quality assured spirometry. But there is also opportunity to enhance care through other high value interventions, such as influenza vaccination and pulmonary rehabilitation. ${ }^{15}$ Falzon et al. are to be commended for incentivising these measures as part of their LES. It has been shown that use of a financial incentive in a hospital to drive implementation of a discharge care bundle for COPD led to improved compliance with best practice interventions and reduced readmission rates. ${ }^{16} \mathrm{It}$ will be interesting to see if Falzon et al., as a consequence of the LES, can show improved outcomes in other aspects of primary care COPD management over and above diagnosis prevalence rates.

Finding the missing millions is an essential aspect of the COPD care pathway, and primary care is well placed to identify the undiagnosed population. However, care needs be taken when designing financial incentives in order to avoid "tick-box" exercises and fragmentation of care. The individual parts of the management pathway for COPD are in place: we know who to look for, how to investigate them, what interventions provide the best value and outcomes, how to manage stable patients, and how to treat them when things go wrong. The importance of integrated, collaborative efforts between different parts of the healthcare system has been discussed in this journal and others. With the high burden of COPD and the current financial situation in many countries around the world, we suggest that the time is right for an integrated incentive and reward system to optimise COPD outcomes with primary care clinicians taking the lead.

Conflicts of interest The authors declare that they have no conflicts of interest in relation to this article.

Commissioned article; not externally peer-reviewed; accepted 12th February 2013; online 21st February 2013

(C) 2013 Primary Care Respiratory Society UK. All rights reserved http://dx.doi.org/10.4104/pcrj.2013.00024

Prim Care Respir J 2013; 22(1): 12-13

\section{References}

1. Nacul L, Soljak M, Samarasundera E, et al. COPD in England: a comparison of expected, model-based prevalence and observed prevalence from general practice data. J Public Health 2011;33(1):108-16. http://dx.doi.org/10.1093/ pubmed/fdq031

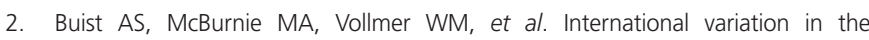
prevalence of COPD (the BOLD Study): a population-based prevalence study. Lancet 
2007;370(9589):741-50. http://dx.doi.org/10.1016/S0140-6736(07)61377-4

3. Jones R. Can early diagnosis and effective management combat the irresistible rise of COPD? Br J Gen prac 2006;56(530):652-4.

4. British lung Foundation. Lost In Translation. 2006. BLF London.

5. National Clinical Guideline Centre. Chronic obstructive pulmonary disease: management of chronic obstructive pulmonary disease in adults in primary and secondary care. London: National Clinical Guideline Centre, 2010.

6. Global Strategy for the Diagnosis, Management and Prevention of COPD, Global Initiative for Chronic Obstructive Lung Disease (GOLD) 2013. Available from: http://www.goldcopd.org/.

7. Department of Health. An Outcomes Strategy for Chronic Obstructive Pulmonary Disease (COPD) and Asthma. Crown,London, 2011.

8. NHS Commissioning Board. The CCG Outcome Indicator Set 2013/14. 2012. Available from: http://www.commissioningboard.nhs.uk/files/2012/12/oisataglance.pdf

9. Falzon C, Soljak M , Elkin SL, Blake ID, Hopkinson NS. Finding the missing millions - the impact of a locally enhanced service for COPD on current and projected rates of diagnosis: a population-based prevalence study using interrupted time series analysis. Prim Care Respir J 2013;22(1):59-63. http://dx.doi.org/10.4104/ pcrj.2013.00008
10. Glasziou $P$, Buchan $H$, Del Mar $C$, et al. When financial incentives do more good than harm: a checklist. BMJ 2012;345:e5047. http://dx.doi.org/10.1136/ bmj.e5047

11. Woolhandler S, Ariely D, Himmelstein DU. Why pay for performance may be incompatible with quality improvement. BMJ 2012;345:e5015. http://dx.doi.org/ 10.1136/bmj.e5015

12. White P. Spirometric screening for COPD: wishful thinking, not evidence. Thorax 2007;62(8):742-3.

13. Levy ML, Quanjer PH, Booker R, Cooper BG, Holmes S, Small IR. Diagnostic spirometry in primary care: proposed standards for general practice compliant with American Thoracic Society and European Respiratory Society recommendations. Prim Care Resp J 2009;18(3):130-47. http://dx.doi.org/10.4104/pcrj.2009.00054

14. Parkes G, Greenhalgh T, Griffin M, Dent R. Effect on smoking quit rate of telling patients their lung age: the Step2quit randomised controlled trial. BMJ 2008; 336(7644): 598-600. http://dx.doi.org/10.1136/bmj.39503.582396.25

15. Gray M, El Trurabi A. Optimising the value of interventions for populations. BMJ 2012;345:e6192. http://dx.doi.org/10.1136/bmj.e6192

16. Hopkinson NS, Englebretsen C, Cooley N, et al. Designing and implementing a COPD discharge care bundle. Thorax 2011;67(1):90-92. http://dx. doi.org/10.1136/ thoraxjnl-2011-200233

\section{The changing face of asthma in Finland: improved recognition and no further increase in symptoms}

\section{See linked editorial by Kainu et al. on pg 64}

\section{*Anders Bjerg ${ }^{1}$}

1 (Post-doctoral) Researcher, Krefting Research Centre, Department of Internal Medicine and Clinical Nutrition, Sahlgrenska Academy, University of Gothenburg, Göteborg, Sweden

*Correspondence: Dr Anders Bjerg, Krefting Research Centre Göteborgs Universitet, Box 424, S-405 30 Göteborg, Sweden Tel: +46(0)707 604459 Fax: +46(0)31786 6730

E-mail: anders.bjerg@gu.se

Over the past half-century the prevalence of asthma and allergic conditions has increased considerably. The magnitude of this increase, as well as its seemingly global occurrence, has led to this being termed the "asthma epidemic". 'The supporting evidence is vast, ranging from symptom-based questionnaires to clinical evaluations and register studies of diagnoses and prescriptions. ${ }^{2}$

However, during the past decade, several studies (predominantly in children) have reported a levelling off of previously increasing trends. Famously, the International Study of Asthma and Allergy In Children (ISAAC) found no further increase of asthma in school-age children and teenagers in several regions. ${ }^{3}$ Other longitudinal crosssectional surveys of children recorded both the aforementioned rise in asthma and the recent plateau. In Aberdeen, Scotland, wheeze and shortness of breath increased considerably between 1964 and 1994 but not from 1994 to 1999. ${ }^{4}$ Similar trends were recorded from 1982 to 2002 in Belmont, Australia and were confirmed by methacholine bronchial responsiveness challenge. ${ }^{5}$
The Nordic countries also experienced a rise in asthma between the 1970's and 1990's in both children and adults. ${ }^{6,7}$ In northern Norway the prevalence of asthma symptoms increased in schoolchildren from 1985 to 1995, and then plateaued until 2000. ${ }^{7}$ In Sweden the prevalence of physician-diagnosed asthma and use of asthma medications increased slightly during the last two decades, both in schoolchildren ${ }^{8}$ and in adults..$^{9,10}$ However, in these studies, symptoms common to asthma were unchanged or even decreased in prevalence. The authors concluded that no real increase in asthma occurred after the 1990's, and that the rise in asthma diagnoses was explained by heightened awareness and changed healthcare practices. $^{8-10}$

This Nordic perspective is further extended to Finland by Kainu and colleagues in this issue of the PCRJ. ${ }^{11}$ Among adults living in Helsinki, the age-adjusted prevalence of physician-diagnosed asthma increased significantly from $6.5 \%$ to $10.0 \%$ ( $P<0.001)$ between 1996 and 2006, as did use of asthma medications (from 5.9\% to $9.2 \%$; $\mathrm{P}<0.001$ ). These upward trends were statistically significant after adjustment for differences in age, smoking and gender between the two populations. However, the same adjusted analyses showed no increase in the majority of symptoms common in asthma, most importantly recurrent wheeze and the "wheeze triad" (subjects experiencing wheeze with breathlessness apart from colds). The prevalence of allergic rhinoconjunctivitis increased from $37.2 \%$ to $44.4 \%$, whilst that of smoking decreased.

So, did asthma increase in Helsinki? It seems that despite a substantial increase in physician-diagnosed asthma, the prevalence of symptoms suggestive of asthma changed little in the population, similar to the recent findings in Sweden. ${ }^{8-10}$ Participation decreased from $76 \%$ to $62 \%$ in the Helsinki study, ${ }^{11}$ which unfortunately did not 